\title{
Features of the educational system in the Kabardino-Balkarian Republic (Russian Federation) in the context of digitalization
}

\author{
Rimma Bagova*, Olga Mikhaylenko, and Budimir Nagoev \\ Kabardino-Balkarian State University named after H.M. Berbekov, 360004, Nalchik, Russia
}

\begin{abstract}
The results of an automated online survey of parents of schoolchildren in the Kabardino-Balkarian Republic (Russian Federation) are presented. The aim of the survey was to study the satisfaction of the parents of schoolchildren with the form of organization and the results of the educational work of the educational organization. The average indicators of parental satisfaction with various aspects of educational work are analyzed. It was revealed that the satisfaction of parents in the areas of educational work differs. Parents are little satisfied with how the school forms positive life goals, high life needs, tolerance for the views and opinions of other people, the development of volitional qualities, and independence. Parents believe that the school does not help the child to believe in themselves, learn to solve life problems, overcome difficulties does not teach the correct behavior in difficult life situations. From their point of view, the school does not sufficiently teach their children to reject nationalism, extremism, corruption; prevention of alcohol and drug addiction and smoking. Also, parents believe that the school does not prepare well enough for a meaningful choice of profession. To increase the efficiency of the organization of educational work, it is recommended to improve the training of future teachers in the process of obtaining higher education. It is necessary to prepare them for professional activity in modern conditions of digital transformation of society and education on the basis of a systematic approach to the organization of educational work and the use of innovative technologies.
\end{abstract}

\section{Introduction}

The federal-state educational standard of general education, following which the work of teachers in the Russian Federation is structured, has made changes to the requirements for school education. Changes in the standard require schools to organize upbringing outside the classroom, which must be complemented by an upbringing in the classroom, while the lesson in recent decades has been perceived only as a learning process. The standard obliges to develop the personality of the student, and not to bring it in line with the general level of upbringing. This is only possible through close interaction between the school and the parents. It has been established that communication between parents and school, strong

* Corresponding author: bagovarimma@mail.ru 
relationships between parents and teachers are important for the long-term results of psychosocial development of children [1]. The involvement of parents in this interaction leads to the fact that they begin to devote more time at home to teaching and raising a child [2]. Therefore, many researchers conclude that children need educational and psychological support from both the school and the family [3]. To actualize the requirements of this standard, KBR schools must develop their education programs starting in September 2021. To study the effectiveness of the educational school work, we have developed automated methods of questioning students and their parents. From February 1 to February 28, 2021, diagnostics of relevant aspects of educational work were carried out in schools of the KBR. 14228 parents of pupils of grades 7-11, from 129 settlements of the KBR, as well as 20417 schoolchildren of 7-11 grades from 135 settlements of the KBR, took part in the survey. A total of 34,645 people completed the interview.

\section{Materials and methods}

The digital transformation of education is changing research methods, methods of obtaining information and methods of analysis [4]. We used the online survey method to examine the attitude of schoolchildren's parents to the parental process in school. The survey was based on filling out an interactive questionnaire form via the Internet, which made it possible to collect data remotely during the COVID-19 pandemic. Online surveys have become a popular research method because they provide the researcher with many opportunities [5]. An online survey has many advantages: it allows to interview a large number of people within a short time, the progress of the survey can be monitored in real-time. When interviewing a large number of respondents, the ability to automatically process data is important. The complete anonymity that online research can provide allows respondents to express their opinions more openly and honestly. Such a survey is comfortable for the respondent because it allows the respondent to choose the time and place for the survey himself.

For questioning parents, we used a comprehensive methodology to study the satisfaction of parents with the life of the educational institution A.A. Andreeva, which was supplemented and automated by us. The methodology makes it possible to identify the parents' assessment of the school's participation in the upbringing of their children's qualities of vital competence, positive behavioral and moral-psychological qualities, and the ability to solve basic life problems. The questionnaire consists of two parts. The first part is aimed at diagnosing attitudes towards the formation of personal qualities, the second part at diagnosing attitudes towards the formation of the ability to solve life problems.

\section{Results}

Parents give the highest rating to the educational work of the school on the formation of such personality traits in their children as honesty in relationships with people, kindness in relationships with people, fairness in relationships with people, and interest in learning. Studies show that a high level of interest in learning is subsequently associated with less absenteeism and higher academic results [6]. To a lesser extent, parents are satisfied with the extent to which school fosters high life needs, will and tolerance for the views and opinions of other people, and positive life goals in their children. The distribution of parental satisfaction levels with the educational work of the school on the formation of behavioral qualities by grades 7 through 11 are shown in Diagram 1 . 


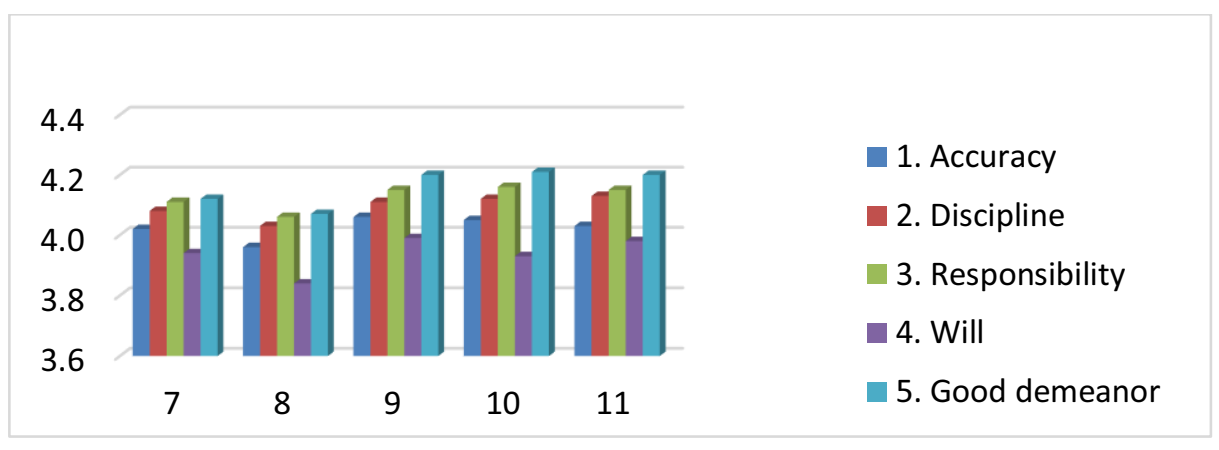

Fig. 1. Block of behavioral qualities

The analysis shows that the structure of parents' assessment of the formation of behavioral qualities does not change with the child's age. To a greater extent, parents are satisfied with the school's formation of good behavior in their children, to a lesser extent with the development of volitional qualities. The development of volitional self-regulation is very important for schoolchildren. Research results have shown that learning strategies for self-regulation of learning had a significant impact on academic motivation and selfefficacy of learners [7].To a greater extent, parents are satisfied with the school's formation of good behavior in their children, to a lesser extent with the development of volitional qualities. The distribution of parental satisfaction levels with the educational work of the school in the formation of qualities related to life competence is shown in Diagram 2.

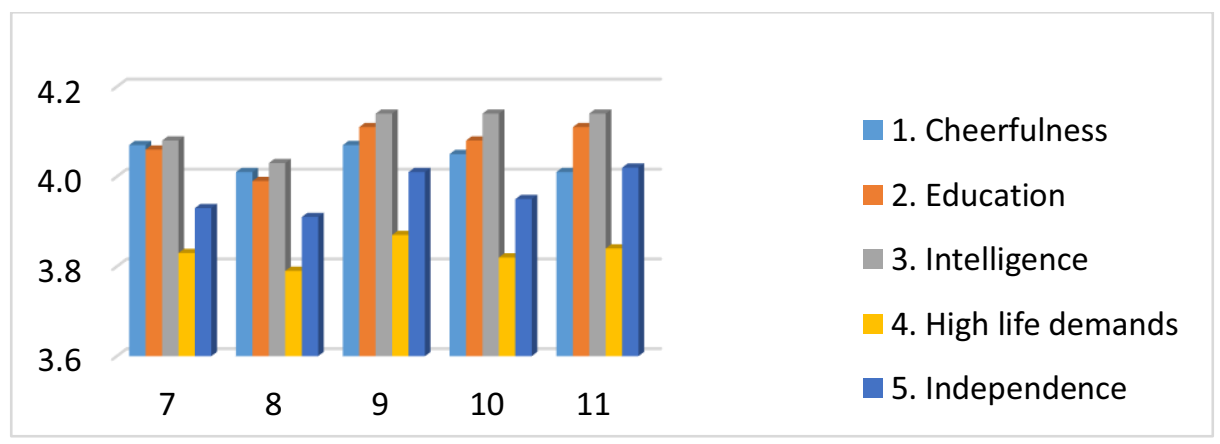

Fig. 2. Block of vital competence

Starting from the 9th grade of the child, parents more highly appreciate the work of the school in the formation of intellectual qualities - intelligence and education. Parents of adolescents rated the formation of their independence lower than the parents of high school students. Low satisfaction with the formation of high demands in life at all ages. The structure of the parent's assessment of the formation of moral and psychological qualities also hardly changes with age. To a greater extent, parents are satisfied with the formation of kindness, honesty, and justice. The formation of sensitivity is rated less highly, the work of the school in the formation of tolerance for the views of others is rated low. 


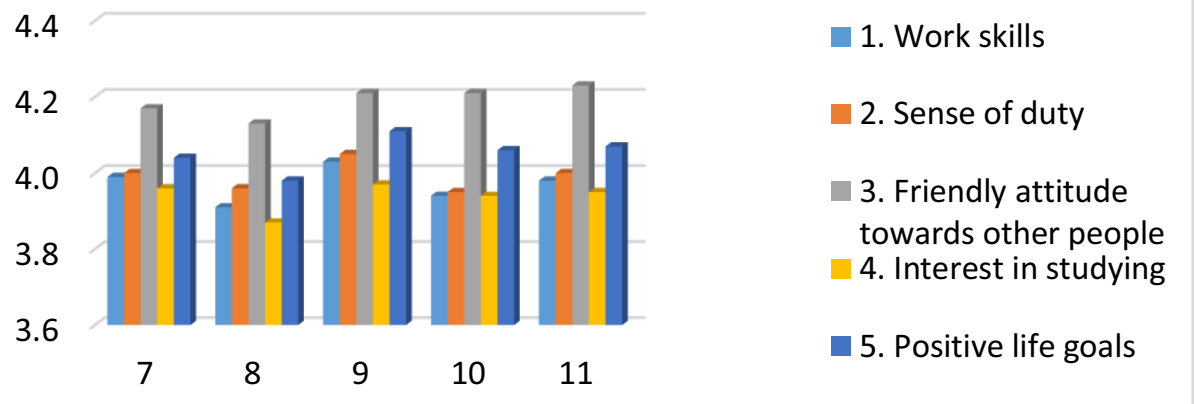

Fig. 3. Additional block

Of the qualities that we included in the additional block of the first part of the methodology for parents, they most highly rated the work of the school in fostering a benevolent attitude towards people in their children, and to a lesser extent - positive life goals. It has been shown that the presence of positive life goals and a positive assessment of the meaning of life affects the preservation of health [8]. Parents are least satisfied with the formation of interest in learning, especially the parents of eighth-graders. This may be due to the well-known decrease in learning motivation in adolescents [9]. An analysis of the average values shows that parents gave a higher rating to the school's ability to empathize with and help people with disabilities, respect for the culture, languages, traditions and customs of the peoples of Russia and respect for nature and ecology. The lowest rated was how the school helps the child to believe in themselves, learn to solve life problems, overcome difficulties, and how the school teaches the correct behavior in difficult life situations. We believe that for the upbringing of these qualities, the development of personal self-determination of schoolchildren is necessary [10]. The parents gave the highest rating to how the school helps the child to communicate correctly with adults and peers.

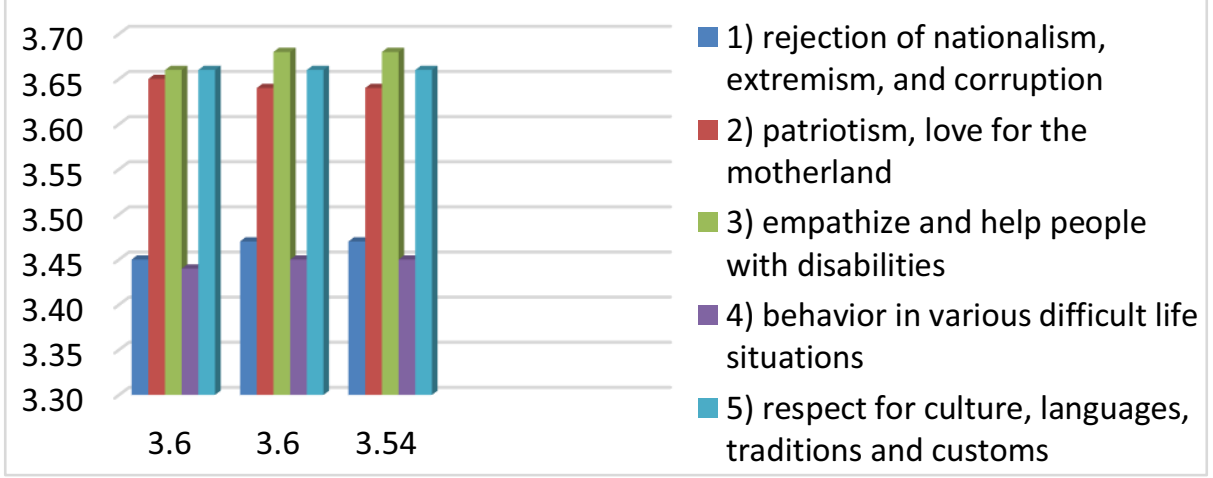

Fig. 4. School helps the child

In all classes, parents highly appreciate how the school teaches the child to respect the environment, empathy for people with disabilities, respect for culture, customs of peoples, patriotism and love for the homeland, interest in physical culture and sports. Also, in all grades, there is a lower assessment by parents of how the school teaches their children to reject nationalism, extremism, corruption; behavior in difficult life situations; interest in 
science and technology (decreases from grade 7 to grade 11); prevention of alcohol and drug addiction and smoking; meaningful choice of profession.

\section{Discussion}

Parents highly appreciated such aspects of the educational work of KBR schools as the formation of honesty, kindness and fairness in relations with people, interest in learning, good behavior, intelligence and education, and a benevolent attitude towards people in their children. Also highly appreciated educational work on the development of the ability to empathize and help people with disabilities, the formation of respect for culture, languages, traditions and customs of the peoples of Russia, respect for nature and ecology, patriotism and love for the homeland, interest in physical culture and sports. To a lesser extent, parents are satisfied with how the school forms positive life goals, high life needs, tolerance for the views and opinions of other people, the development of volitional qualities, and independence. Parents believe that the school does not help the child to believe in themselves, learn to solve life problems, overcome difficulties, does not teach the correct behavior in difficult life situations. From their point of view, the school does not sufficiently teach their children to reject nationalism, extremism, corruption; prevention of alcohol and drug addiction and smoking. Also, parents believe that the school does not prepare well enough for a meaningful choice of profession. From our point of view, in order to overcome the indicated problems of upbringing in school, it is necessary to improve the training of future teachers in the process of obtaining higher education. It is necessary to prepare them for professional activity in the modern conditions of digital transformation of society and education [11]. It is necessary to form in them a systematic approach to the organization of educational work. Education at school should be organized in accordance with the desired "image" of the graduate and based on the development of students' motivation for personal and professional self-development [12]. It is necessary to build the training of future teachers and educational work at school on the basis of project work. Research shows that participation in projects develops motivation, independence, and the ability to solve problems [13]. When designing educational work, it is necessary to take into account the individual and age characteristics of the student, the zone of proximal development [14]. Innovative technologies of education should be developed on the basis of modern achievements of psychological science [15].

\section{Conclusions}

To increase the efficiency of the organization of educational work in schools of the KBR, taking into account the analysis carried out, the following can be proposed. To develop at the level of the Ministry of Education, Science and Youth Affairs of the KabardinoBalkarian Republic the concept of "the image of a school graduate in the KBR". Based on this "image", one can evaluate the effectiveness of the educational work of a particular school. Make the monitoring system of educational work in KBR schools regular, coverage of parents and students in diagnostics more massive and informal. Conduct refresher courses for deputy school principals of the KBR, educational psychologists, and class teachers in the field of innovative technologies of upbringing, and psychological and pedagogical support of education based on the IPPFSO KBSU. The Ministry of Education, Science and Youth Affairs of the Kabardino-Balkarian Republic to ensure the possibility of financing the winners of competitions of educational projects for class teachers of KBR schools. To develop a scientific and educational Internet portal of the KBR, which will present scientific and educational, and popular science materials for teachers, parents, 
schoolchildren on topical topics. Encourage class teachers to more often create immediate conditions and situations in which students will exhibit the necessarily required personality traits.

\section{References}

1. Joshua Raclaw, Jena Barchas-Lichtenstein, Abby Bajuniemi, Response practices and recipient design, Discourse, Context \& Media 38, (2020).

2. Melissa A. Barnett, Katherine W. Paschall, Ann M. Mastergeorge, Christina A. Cutshaw, Shannon M. Warren, Early Childhood Research Quarterly 53, 260-273 (2020).

3. Leena Holopainen, Katariina Waltzer, Nhi Hoang, Kristiina Lappalainen, International Journal of Educational Research 104 (2020).

4. Veraksa N., Shannon N. B Frischherz, The Application of "Metathinking" To Analyse And Inform Contemporary Discourse On" Digital Transformation", XVI European Congress Of Psychology, 382-382 (2020).

5. Abbie E. Goldberg, Juli Anna Z. Smith, Early Childhood Research Quarterly 40, 174187 (2017).

6. T.E. Virtanen, E. Räikkönen, M.C. Engels, K. Vasalampi, M.-K. Lerkkanen, Learning and Individual Differences 86, 101972 (2021).

7. Masoud Gholamali Lavasani, Fatemeh Sadat Mirhosseini, Elahe Hejazi, Maryam Davoodi, Procedia - Social and Behavioral Sciences 29, 627-632 (2011).

8. M. Mokaeva, M. Nogerova, R. Bagova, R. Malkarova, S. Hachetlova, M. Kheimasheva, Dilemas Contemporaneos-Educacion Politica Y Valores 6 (93) (2019).

9. H.M.G. Watt, Child Development 75, 1556-1574 (2004).

10. R. Bagova, Subjective space of possible action and lever of subjectivity of students of higher education, ECCE 2018, VII International Conference Early Childhood Care and Education. The European Proceedings of Social \&Behavioural Sciences, XLIII, 379385 (2018), Moscow, Published by the Future Academy.

11. O. Mikhailenko, M. Vakulenkova, E. Sharova, Propositos Y Representaciones 8 (749) (2020).

12. R. Bagova, L. Baysieva, O. Mikhailenko, M. Nogerova, European Proceedings of Social and Behavioural Sciences 58, 150-156 (2019).

13. Pengyue Guo, Nadira Saab, Lysanne S. Post, Wilfried Admiraal, International Journal of Educational Research 102, 101586 (2020).

14. L, Vygotsky, Mind in Society: The Development of Higher Psychological Processes, 1978.

15. Helen Crompton, Matthew Bernacki, Jeffrey A Greene, Current Opinion in Psychology 36, 101-105 (2020). 